\title{
Study of the Composition of the Mining Industry Rubber Waste Pyrolyzates
}

\author{
Evgeniya Makarevich ${ }^{1}$, Andrey Papin $^{1}$, and Alexander Chernik ${ }^{2}$ \\ ${ }^{1}$ T.F. Gorbachev Kuzbass State Technical University, 650000, Russian Federation \\ ${ }^{2}$ Belarusian State Technological University, 220006, Republic of Belarus
}

\begin{abstract}
The study of the composition of the mining industry rubber waste pyrolyzates is an urgent research task. The study of the rubber waste pyrolyzates: solid carbon residue and various fractions of the pyrolysis liquid is presented in the work. A high content of sulfur compounds in all fractions of the pyrolysis liquid was found. The possibilities of improving the quality characteristics of the solid carbon residue and reducing sulfurcontaining substances in the fractions of the pyrolysis liquid, which will allow their use as adsorbents and motor fuels, are considered.
\end{abstract}

\section{Introduction}

The development of the mining industry leads to an increase in the amount of rubber waste, the main component of which is obsolete car tires and conveyor belts. Their disposal is a serious environmental problem, since these polymeric materials are difficult to decompose. With increasing interest in waste processing, pyrolysis is considered to be an alternative process for extracting commercial benefits from rubber waste. Pyrolysis has advantages over other methods of disposal of waste tires: it is converting into commercial products, the possibility of using pyrolysis products as fuel and adsorbents.

To increase economic efficiency and expand the scope of application of pyrolysis products, further research is needed in the field of technological conditions, optimization, characterization and processing of goods from pyrolysis products.

Ultimate analysis shows that tire rubber contains about $80 \mathrm{wt} \% \mathrm{C}, 7 \mathrm{wt} \% \mathrm{H}, 0.4 \mathrm{wt} \%$ $\mathrm{N}, 1.5 \mathrm{wt} \% \mathrm{~S}, 3 \mathrm{wt} \% \mathrm{O}$ and $8 \mathrm{wt} \%$ of inorganic substances. When pyrolyzing worn tires, three fractions are obtained: a solid residue (30-40 wt \%), a liquid fraction (40-60 wt \%) and a gas fraction (5-20 wt\%). The yield of each fraction depends on the process conditions, such as temperature, pressure, heating rate, particle sizes, heat transfer system, catalysis [1].

The solid residue contains carbon black and inorganic substances.

With increasing the pyrolysis process temperature, an increase in the yield of liquid and gas fractions occurs. The liquid fraction is the most important product of the tire pyrolysis process. The resulting liquids are a complex mixture of organic compounds containing a large number of aromatic substances, nitrogen-containing and oxygencontaining compounds. Their calorific value is higher than that of industrial heating oils, but the sulfur content exceeds the limit value. A significant amount of valuable light-end hydrocarbons, such as benzene, toluene, limonene, etc., can be obtained from the liquid 
fraction. There are also significant proportions of polycyclic aromatic hydrocarbons, such as naphthalene, phenanthrene, diphenyl, etc.; their concentration, as well as the total content, increases significantly with increasing temperature.

The gaseous fraction consists of non-condensable organic substances and can be used as fuel in the pyrolysis process [2].

\section{Materials and methods}

Products of pyrolysis of tires of KEK+ LLC were taken (Kaltan, Kemerovo Region, Russia) as objects of research. The structural features of the compounds of the the carbon residue composition and the pyrolysis liquid fractions were studied by IR spectroscopy. The adsorption activity of the solid carbon residue was determined by the methylene blue adsorption method. Proximate and ultimate analyses of the solid carbon residue were carried out according to State Standards GOST R 53357-2013 and GOST R 53355-2009. The extraction desulfurization method was used to reduce the sulfur content in the pyrolysis liquid fractions.

\section{Results and discussion}

Proximate and ultimate analyses of the solid carbon residue were carried out. The composition is investigated. It was found that the carbon residue has high ash values (8.9$20.40 \%$ ), volatiles yield (7.50-16.55\%), and sulfur content (3-5\%). The results of elemental analysis showed that the solid pyrolysis residue contains about $80 \mathrm{wt} \% \mathrm{C}, 1.5$ wt. $\%$ N.

The IR spectroscopy method was used to study the structural features of compounds of the carbon residue composition (Fig. 1). It was found that there are absorption bands at $2400-2300 \mathrm{~cm}^{-1}$ and $2150-1950 \mathrm{~cm}^{-1}$, which is caused by stretching vibrations of carbon atoms in alkanes and alkyl fragments, vibrations of the $(\mathrm{C} \equiv \mathrm{C})$ group in alkynes, and groups $(\mathrm{N}=\mathrm{C}=\mathrm{S}, \mathrm{SC} \equiv \mathrm{N})$ in thiocyanates.

The absorption bands in the region of $1750-1560 \mathrm{~cm}^{-1}$ can correspond to the carbonyl group $(\mathrm{C}=\mathrm{O})$, the group $(\mathrm{C}=\mathrm{C})$ of alicyclic compounds, and the group $(\mathrm{C}-\mathrm{C})$ of aromatic hydrocarbons.

The absorption band in the region in the range 1060-1040 $\mathrm{cm}^{-1}$ corresponds to sulfoxide, and the bands in the range $800-690 \mathrm{~cm}^{-1}$ characterize other sulfur-containing compounds.

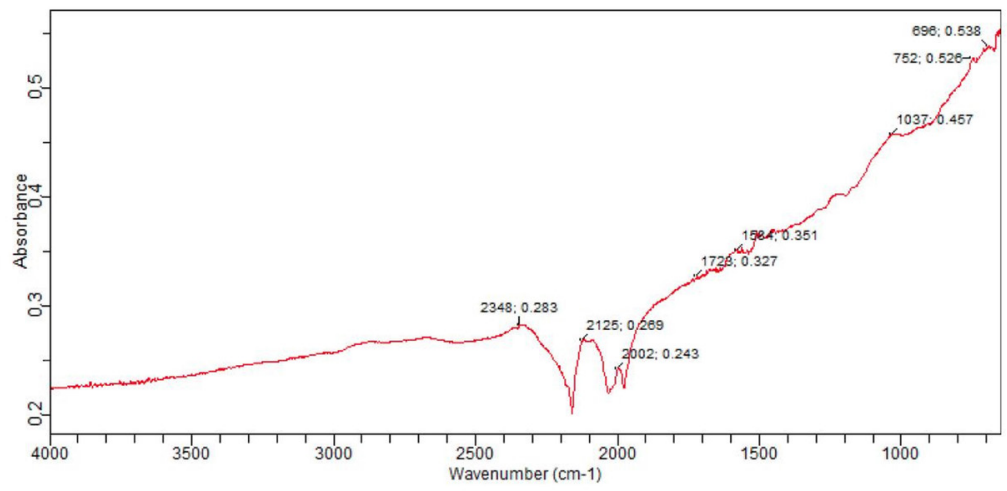

Fig. 1. IR spectrum of the solid carbon residue of tire pyrolysis. 
The high toxicity and pungent odor of the solid carbon residue, caused by violations of the process flow and the absence of aromatization and polycyclization reactions, which intensify at higher temperatures, do not allow using it as an adsorbent and fuel. Therefore, it becomes necessary to upgrade the carbon residue to expand the scope of its possible application.

The carbon residue was upgraded by thermal processing. As a result, the qualitative characteristics of the product improved, the ash content $(6.5-10.0 \%)$, the yield of volatile substances $(0.27-0.38 \%)$, and the sulfur content $(0.25-0.5 \%)$ decreased. Thus, high-quality raw materials were obtained for the production of adsorbents and smokeless fuel. Ultimate analysis showed that the upgraded carbon residue contains $86 \mathrm{wt} \% \mathrm{C}$, about $1.0 \mathrm{wt} \% \mathrm{~N}$.

The structural features of the compounds of the processed carbon residue compositions were studied by IR spectroscopy (Fig. 2). It was established that as a result of upgrading, multiple $\mathrm{C}-\mathrm{C}, \mathrm{C}-\mathrm{O}$ bonds are destroyed, as evidenced by a decrease in the intensity of absorption bands in the region of $1750-1560 \mathrm{~cm}^{-1}$. The splitting of organic polysulfide bonds also occurs; this can be seen by the absence of absorption bands in the range of 1060$1040 \mathrm{~cm}^{-1}$ and $800-690 \mathrm{~cm}^{-1}$.

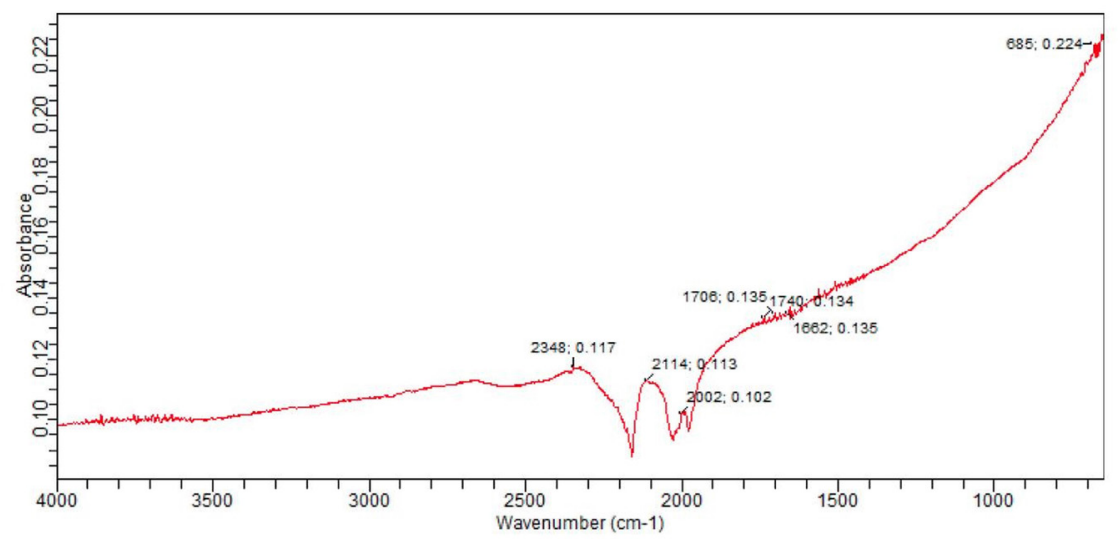

Fig. 2. IR spectrum of depleted solid carbon tire pyrolysis residue.

The possibility of using the upgraded carbon residue as an adsorbent was investigated. The upgrading was found to increase the specific surface of the carbon residue.It has been established that after upgrading, the total pore volume doubles.

The methylene blue adsorption activity of the solid carbon residue characterizes the number of macropores, since large and flat methylene blue molecules can be adsorbed mainly on macropores. It was found that, when upgraded, the methylene blue adsorption activity of the solid carbon residue significantly increases.

In the study of iodine adsorption activity, the sorption process proceeds over the entire surface of the adsorbent, both in macro- and in micropores, due to the small size of the iodine molecules. It has been found that the iodine adsorption activity of solid carbon residue depends on the particle size of the adsorbent and the reaction time.

The liquid fraction has a dark brown color, a sharp toxic smell with a characteristic shade of products containing sulfur compounds. The fractional composition of the liquid tire pyrolysis product was determined according to State Stndard GOST R 57036-2016 "Petroleum products. Determination of fractional composition at atmospheric pressure" using ARN-LAB-1 device. The beginning of boiling was observed at a temperature of $55^{\circ} \mathrm{C}$. It was established that the liquid product composition contains a petroleum fraction in an amount of $4 \%$, a gasoline fraction in an amount of $21 \%$, a kerosene fraction in an 
amount of $18 \%$, a diesel fraction in an amount of $47 \%$, fuel oil in an amount of $10 \%$ [29].

The molecular structure of each obtained fraction was studied by infrared spectroscopy (Fig. 3-6). It was established that the composition of all fractions contains non-cyclic saturated and unsaturated hydrocarbons, aromatic compounds. There are absorption bands at 2950, 2930-2925, 2860-2853, $2840 \mathrm{~cm}^{-1}$ and near 1470-1465, 1370 $\mathrm{cm}^{-1}$, which is due to fluctuations in the methyl and methylene groups that make up the alkanes. The absorption bands that characterize the presence of alkanes in the region of 2950-2840 $\mathrm{cm}^{-1}$ (four bands), at 1465 and $1375 \mathrm{~cm}^{-1}$, are clearly visible. Absorption bands in the region of $3100-3010,1800-1790 \mathrm{~cm}^{-1}, 1510,1430-1410,670 \mathrm{~cm}^{-1}$ may correspond to benzene or its substituted compounds, but the region of $3100-3010 \mathrm{~cm}^{-1}$ may also correspond to the vibrational region of bonds in alkanes. The identification of groups by the absorption bands of 1360 and $1090 \mathrm{~cm}^{-1}$ is not reliable; it is possible that they characterize the vibrations of methyl groups in branched alkanes. A wide band in the range of 915-690 $\mathrm{cm}^{-1}$ characterizes sulfur-containing compounds. The amount of sulfurcontaining compounds increases with increasing distillation temperature. The highest value is recorded in fuel oil.

The information content of IR spectra for sulfur compounds is very limited. S- S and $\mathrm{C}-\mathrm{S}$ bonds are low-intensity and not characteristic, their position strongly depends on the rest of the molecule. For example, thiophene gives a spectrum similar to an aromatic compound $\left(\mathrm{C}-\mathrm{S}\right.$ bond $\left.v=720 \mathrm{~cm}^{-1}\right)$. When studied, sulfur compounds oxidation is often carried out and they are converted to sulfoxides and sulfones, which have very distinct characteristic absorption bands and high intensity absorption bands (sulfoxide in the range of 1060-1040 $\mathrm{cm}^{-1}$, sulfone - $1160-1120 \mathrm{~cm}^{-1}, 1350-1300 \mathrm{~cm}^{-1}$ ).

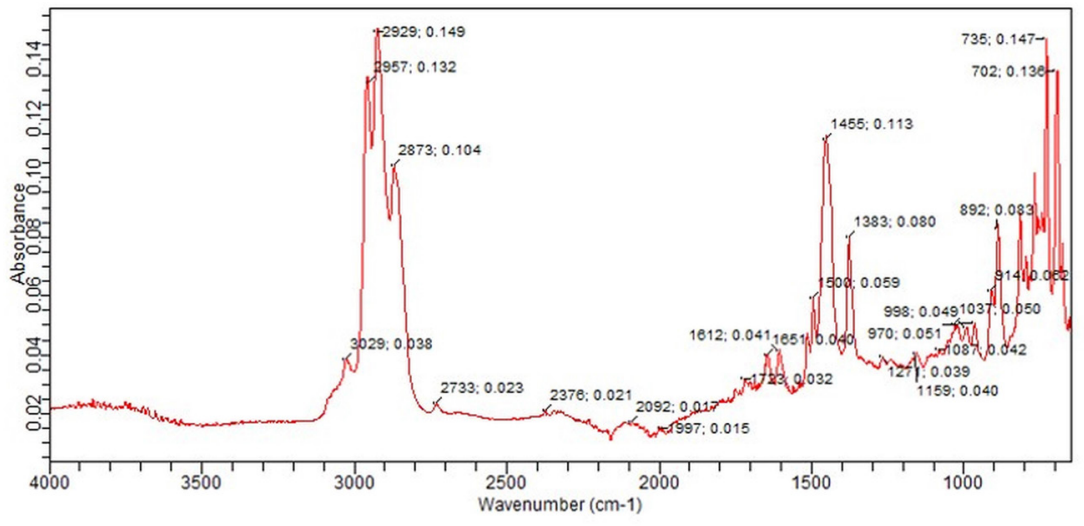

Fig. 3. IR spectrum of gasoline fraction $\left(t=100-180^{\circ} \mathrm{C}\right)$ 


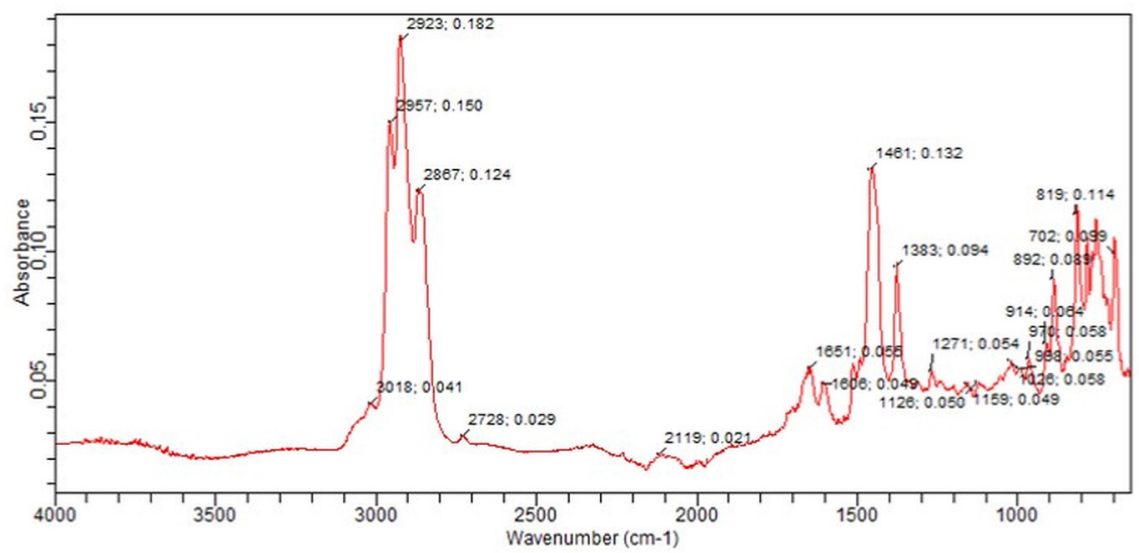

Fig. 4. IR spectrum of kerosene fraction $\left(t=180-240^{\circ} \mathrm{C}\right)$

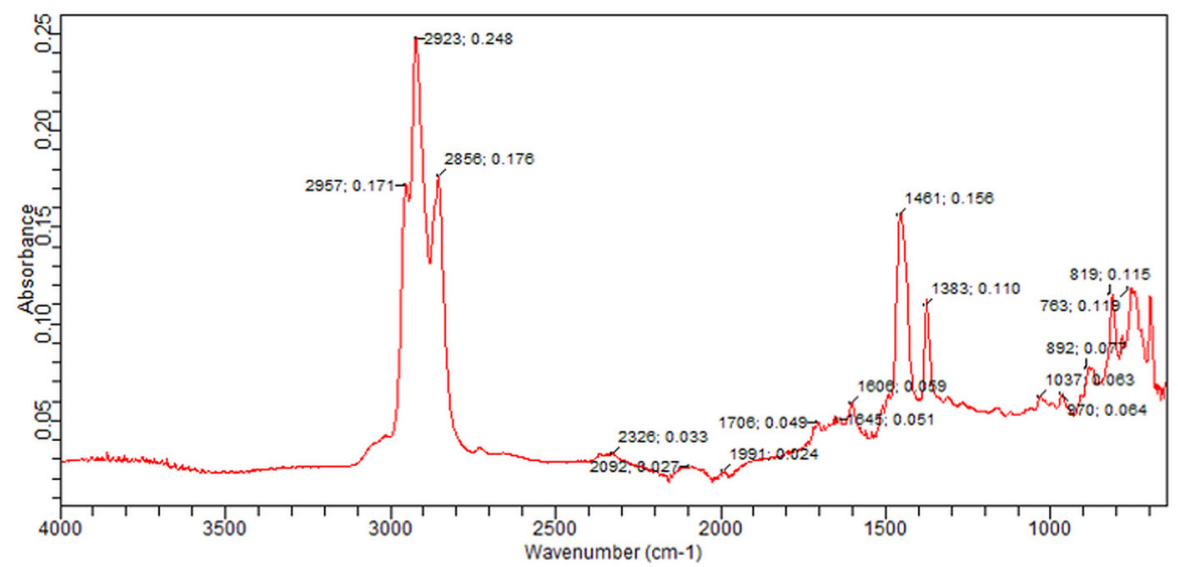

Fig. 5. IR spectrum of diesel fraction $\left(t=240-350^{\circ} \mathrm{C}\right)$

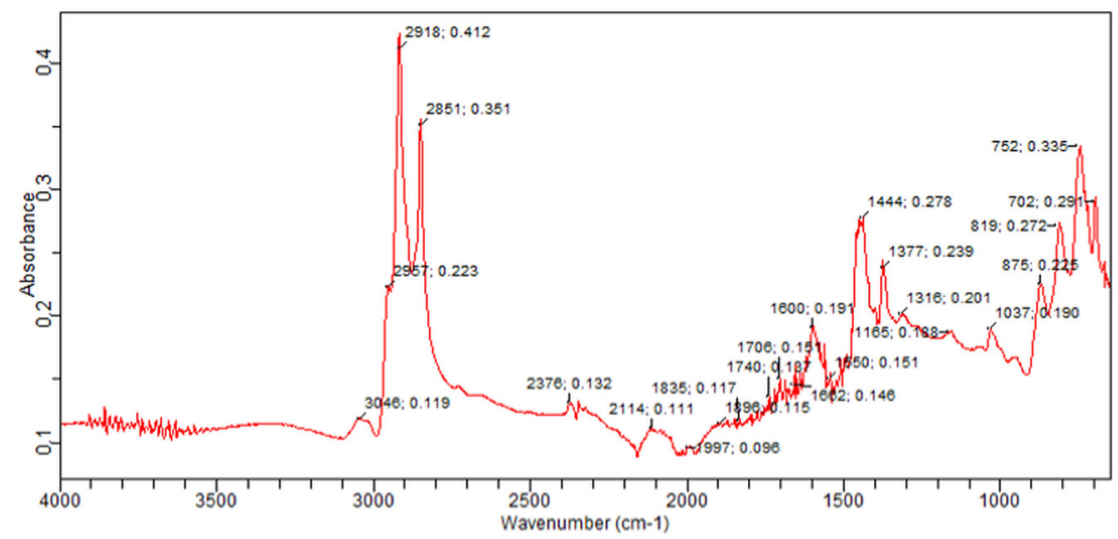

Fig. 6. IR spectrum of fuel oil $\left(t>350^{\circ} \mathrm{C}\right)$ 


\section{Conclusion}

The composition of the rubber pyrolyzates - solid carbon residue and various fractions of the pyrolysis liquid - is investigated.

It was found that the obtained solid carbon residue has low quality characteristics, a high content of sulfur compounds; therefore, upgrading is required to expand the scope of its possible applications. After the solid carbon residue upgrading, the quality of the product improved, the sulfur content decreased, and the adsorption activity increased.

As a result of a comparative analysis of the obtained spectra of the fractions isolated from the pyrolysis liquid with the spectra of similar oil fractions, it was found that the composition of the gasoline, kerosene, diesel fractions and fuel oil isolated from the pyrolysis liquid differs from the composition of similar oil fractions in the content of organosulfur compounds. Therefore, in order to use the obtained products as motor fuels, preliminary desulfurization is required.

There are a number of methods for the desulfurization of petroleum feedstock used to remove organic sulfur compounds from liquid fuels: demercaptanization, biodesulfurization, hydrotreating, extraction and adsorption methods, and oxidative desulfurization.

The purpose of sulfur removal is to reduce emissions of sulfur oxides, which are formed during the burning of sulfur compounds, into the atmosphere. It is also necessary to remove sulfur, as it has an interfering effect on catalysts for oil refining processes. Sulfur removal leads to improved quality of commercial fuels.

The main industrial process aimed at the sulfur removal is catalytic hydrodesulfurization, in which sulfur compounds are destroyed, forming hydrogen sulfide and the hydrocarbon part of the raw material molecules is restored and stored in the target liquid products.

The most reliable and affordable methods for the isolation of organic sulfur compounds are oxidation by various oxidizing agents, silica gel and alumina adsorption, sulfuric acid and alkaline extraction, as well as catalytic methods: hydraulic treating and biodesulfurization [10].

Currently, extraction desulfurization of fractions of the mixtures of organic substances to reduce the sulfur content is actively developing, especially in diesel fuels [10]. The extraction is carried out under mild conditions; the extraction processes do not change the chemical structure of the diesel components. The extraction process is based on the better solubility of sulfur-containing substances and aromatic hydrocarbons compared with nonaromatic hydrocarbons in certain polar solvents. The efficiency of desulfurization depends on the choice of solvent, the chemical activity of the removed sulfur-containing components and a number of other factors. Extraction desulfurization also has significant drawbacks. Carrying out extraction on an industrial scale, under certain conditions, may be accompanied by fuel losses, which leads to a decrease in the yield of a valuable processed product. At the same time, desulfurization turns to be incomplete, which does not allow using it without using other types of desulfurization methods.

In this work, among the solvents used in the processes of extraction desulfurization, dimethylformamide (DMF) and acetonitrile were used. Dimethylformamide has been found to be a good solvent. The use of dimethylformamide to remove sulfur compounds from fractions of the pyrolysis liquid allows achieving good results in extraction desulfurization. Experimental results showing that dimethylformamide can remove up to $85.0 \%$ of thiophene, $90.0 \%$ of dibenzothiophene and $65.0 \%$ of dimethyldibenzothiophene were obtained. The possibility to re-use it in processing without a significant decrease in efficiency when removing these sulfur-containing components was also noted. 


\section{References}

1. S. Murugan, Fuel, 87, 2111 (2008)

2. S. Murugan, Engines, 28, 12, 2743 (2008)

3. O. Arpa, Fuel Process Technology, 91, 1241 (2010)

4. M. Juma, Slovak University of Technology, 9, 88 (2006)

5. S. Hariharan, Fuel, 104, 109 (2008)

6. A. Sharma, Energy Conversion and Management, 93, 289 (2008)

7. S. Murugan, Fuel processing technology, 90, 67 (2010)

8. D. N. Nakamura, Oil and Gas Journal, 27, 105 (2007)

9. M. F. Ali, Fuel, 85, 1354 (2006)

10. Q. Huo, Energy \& Fuels, 24, 7, 3764 (2010) 